\title{
SUPERESTIMAÇÃO DOS INDÍCES DE INFLAÇÃO
}

\author{
Autor: Stephen Charles Kanitz \\ Professor Titular do Departamento de Contabilidade e Atuaria
} da Faculdade de Economia, Administração e Contabilidade da USP.

\section{A Razão do Fracasso dos Planos de Estabilização}

Os resultados desanimadores dos 5 últimos planos de estabilização de preços geram uma suspeita de que ainda existe algum mecanismo de inflação não diagnosticado. Algo que não se encontra na literatura econômica, algo peculiar à economia brasileira. Afinal tudo já foi tentado e a inflação persiste.

A maioria absoluta das pessoas está convicta de que os índices de preços no Brasil são ligeiramente subestimados. Uma inflação real de $9 \%$ acaba sendo calculada como $8,97 \%$ e assim por diante.Talvez seja por isto que ninguém jamais considerou a possibilidade dos índices de preços, por alguma razão, serem superestimados.

Suponha leitor, por um momento, que esta hipótese seja verdadeira. Que uma inflação real de $8 \%$, ao ser publicada como $10 \%$. Nestas condições, nenhum plano, por melhor que fosse, conseguiria debelar a inflação. Uma inflação real de $8 \%$, ao ser publicada como 10\%, aumentaria o patamar da inflação numa espiral incontrolável. Além disso, o governo estaria pagando ao longo do tempo um juro real sobre a divida de $2 \%$ acima do necessário, pressionando o déficit e afundado o inexoravelmente as finanças publicas. O diagnóstico porém seria a de que o déficit publico é o causador da inflação, não a metodologia de calculo.

Já se suspeita há algum tempo de que os índices de preços são mal calculados. Gasta-se em média US\$20.000, por mês para calcular um índice, entre custos de pesquisadores, digitadores etc. Valor muito baixo para se ter um índice,com a segurança e qualidade necessária para a situação brasileira. Devemos estar perdendo $10 \%$ do PIB ou em torno de US $\$ 50$ bilhões de dólares com a ineficiência gerada pela inflação.

Índices onde o custo de elaboração é de somente US $\$ 20.000$ devem conter imprecisões aceitáveis quando a inflação é reduzida, mas extremamente danosas quando a inflação é elevada.

Este arquivo mostra uma das imprecisões que ocorre quando a inflação é elevada e que acarreta uma super-estimação da inflação.

Existem dezenas de causas já conhecidas que geram a inflação, todas já do conhecimento da nação e já combatidas no passado. De nada adianta persegui-las se os índices de inflação superestimadas a realidade. Não é difícil imaginar que uma nação, que por alguma razão superestime a inflação, jamais conseguirá debelar esta inflação qualquer que seja o numero de planos.

Iremos provar que quando a inflação aumenta, os índices gerais de preços são super-estimados. Quando a inflação cai, os índices são sub-estimados, existindo portanto uma simétrica.

Um eletrodoméstico que figura no índice de preços é pesquisado em doze lojas, seus preços coletados e obtem-se uma média. Só que uma dona de casa que pesquisa 12 lojas, acaba comprando pelo preço mais barato e não pelo preço médio. Ou seja, os preços coletados são superiores aos preços comprados. Aos pesquisadores não é dado uma soma de dinheiro para fazer compras da melhor forma possível, como faz um consumidor. Mas esta não é principal razão da superestimação de preços no Brasil. Este exemplo tem o a função de desmistificar a concepção generalizada de que os índices de preços são subestimados.

A variável que explica a superestimação da inflação no Brasil chama-se prazo de crédito, que é o período de tempo que as empresas industriais concedem os seus clientes para pagar as suas compras ou duplicatas. A medida no Brasil é de 28 dias mais ou menos.

Por várias razões, os índices de preços no Brasil acabam captando os preços a prazo, preços que somente serão pagos 28 dias após a coleta de preços. Isto simplificando ao extremo, significa que os índices de preços acabam incluindo hoje, os preços de amanhã. Se a taxa de inflação for estável, tudo bem. Mas se a taxa for crescente, a inflação é superestimação faz com que o patamar da inflação sem parar.

Se a taxa for decrescente, como ocorre logo após a um congelamento, a taxa da inflação é subestimada. O índice de $0 \%$ em março de 1986, era um mito, como todos desconfiam. Na realidade a inflação foi de $5 \%$, mas sob o efeito da subestimação a inflação publicada saiu $0 \%$. 
A tabela I ilustra este fenômeno claramente, apesar de ser uma simplificação de como as empresas estabelecem os seus custos de vendas.

Vejamos exatamente o que ocorre num país com aumento de taxa inflacionária. A inflação, pelas dezenas de razões já apontadas pela literatura, sobe de $1 \%$ em novembro para $4,5 \%$ no mês de dezembro. Os juros passam de $3 \%$ a $6,6 \%$ ao mês. A matéria prima dos fabricantes passa de $\mathrm{Cr} \$ 100$ para 104.5. Como prazo de crédito é de 28 dias, as despesas financeiras dependem somente da taxa de juros, e o preço final sai exatamente $\operatorname{Cr} \$ 110.9$.

Apesar da inflação usada neste calculo de preços ter sido de somente $4,5 \%$, os órgãos divulgadores de inflação irão comparar os preços de $\operatorname{Cr} \$ 102.0$ do mês de novembro e $\operatorname{Cr} \$ 110.9$ de dezembro e captar uma inflação de 7,9, superestimado a inflação, que por DEFINIÇÃO foi só de $4,5 \%$.

TABELA I

\begin{tabular}{|c|c|}
\hline $\begin{array}{l}\text { I Inflação Real } \\
\text { Juro Real } \\
\text { Juros Nominais }\end{array}$ & $\begin{array}{l}1.0 \\
2.0 \\
3.0\end{array}$ \\
\hline $\begin{array}{l}\text { Matéria Prima Cz\$ } \\
\text { Prazo.Créd. (dias) } \\
\text { Desp. Financeiras } \\
\text { Preço Final Cz\$ }\end{array}$ & $\begin{array}{c}100.0 \\
28 \\
2.8 \\
102.8\end{array}$ \\
\hline
\end{tabular}

Inflação Publicada

7.9

A bola de neve está montada. A caderneta é seguida corrigida em 7,9\% +0,5\% e o resto da economia também, gerando uma espiral inflacionária sem fim.

Previsão feita em agosto de 1986 para o Plano Cruzado

Inflação reprimida de $3,5 \%$ gera boa parte da inflação do período.

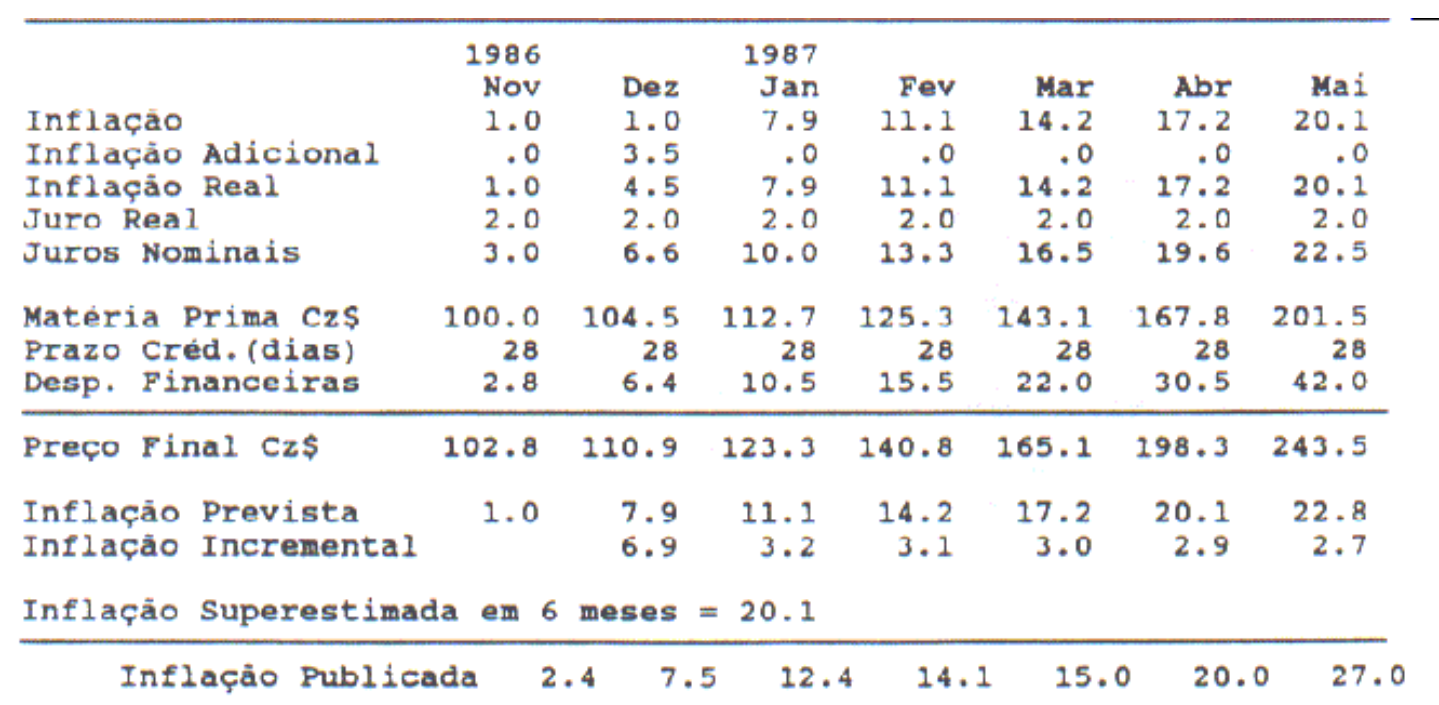

O insucesso do Plano Collor, não esperado pelo Presidente Collor, e por ninguém em tão curto prazo, é explicado por este efeito. O Plano Collor mexeu com as duas variáveis importantes deste fenômeno: A taxa de juros e prazo de crédito, e de 15 dias, antes do Plano, para 45 a 60 dias em média, depois do plano. Era uma única forma das empresas começarem a vender. Isto, pelo exposto, acarretou uma superestimação ainda maior da inflação.

Quanto maior o prazo de crédito, maior a superestimação. Em um segundo momento, o Banco Central aumentou as taxas de juros dentro da linha monetarista.

Veja uma simulação do efeito de um aumento de juros: 


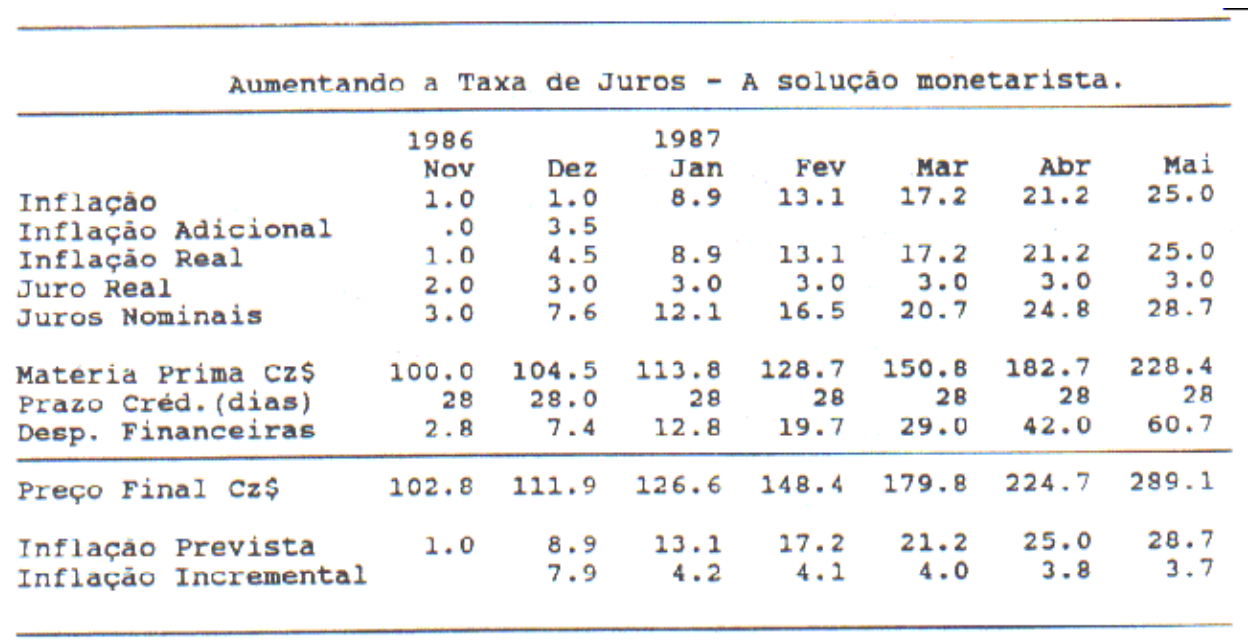

Inflação superestimada em 6 meses $=26.7$

A aceleração da inflação no meses de outubro, novembro e dezembro, que sempre ocorre na economia brasileira, é explicada pelo discreto aumento de prazo de crédito dado pelas empresas no final do ano para incentivar as vendas de Natal.

Aumentando o prazo de Crédito

Normalmente antes do Natal o prazo aumenta 4 dias.

No Plano Collor o prazo passou de 15 para 60 dias.

\begin{tabular}{|c|c|c|c|c|c|c|c|}
\hline \multicolumn{8}{|l|}{-} \\
\hline & 1986 & Dez & 1987 & Fey & Mar & Abr & $\mathrm{Mai}$ \\
\hline Inflaçào & 1.0 & 1.0 & 8.8 & 13.6 & 18.9 & 24.9 & 31.6 \\
\hline Inflaçao Adicional & .0 & 3.5 & & & & & \\
\hline Inflação Real & 1.0 & 4.5 & 8.8 & 13.6 & 18.9 & 24.9 & 31.6 \\
\hline Juro Real & 2.0 & 2.0 & 2.0 & 2.0 & 2.0 & 2.0 & 2.0 \\
\hline Juros Nominais & 3.0 & 6.6 & 11.0 & 15.8 & 21.3 & 27.4 & 34.2 \\
\hline Materia Prima $\mathrm{C} z \$$ & 100.0 & 104.5 & 113.7 & 129.1 & 153.5 & 191.7 & 252.2 \\
\hline Prazo Cred. (dias) & 28 & 32 & 32 & 32 & 32 & 32 & 32 \\
\hline Desp. Financeiras & 2.8 & 7.4 & 13.4 & 21.9 & 35.1 & 56.4 & 92.9 \\
\hline Preço Final Cz\$ & 102.8 & 111.9 & 127.0 & 151.1 & 188.6 & 248.2 & 345.2 \\
\hline Inflação Prevista & 1.0 & 8.8 & 13.6 & 18.9 & 24.9 & 31.6 & 39.1 \\
\hline Inflaçào Incremental & & 7.8 & 4.8 & 5.3 & 6.0 & 6.7 & 7.5 \\
\hline
\end{tabular}

\footnotetext{
Inflação superestimada em 6 meses $=48.4$

Mas não é somente o insucesso do plano Collor que se explica por este efeito.
}

A simulação do Plano cruzado foi extraída de um relatório elaborado em junho de 1986, para o Ministério do Planejamento, apontado os prováveis rumos ao Plano Cruzado, caso a superestimação do Plano Cruzado, caso a superestimação da inflação não fosse sanada. O assustador é observar da espiral inflacionária que esta superestimação da inflação brasileira gera, fruto de um único aumento de 3,5\% da inflação no mês de Dezembro, que termina em 27,9\% no mês de Julho.

A inflação prevista pela simulação e a inflação que realmente ocorreu no período são muito semelhantes. As simulações que fizemos do Plano Bresser e Plano Verão mostram sempre a mesma coisa: a superestimação da inflação brasileira, é a grande culpada pelo fracasso dos planos, muito mais do que déficit publico, a falta de competitividade ou a margem de lucro. 
Sem dúvida, existe uma variável nova que não aparece na literatura econômica americana por duas razões: a primeira, porque a maioria das empresas americanas vendem à vista, o comprador é financiado pelos bancos, não pelo vendedor. A segunda, por que as taxas de juros e a inflação são muito baixas, e a superestimação é mínima, especialmente com inflações mais ou menos estáveis, onde diminuições de preços se intercalam com aumentos. Este fenômeno ocorre especialmente nos países de inflação elevada, como a nossa.

Este efeito também ocorre nos Estados Unidos

Mais como a inflação é muito reduzida a superestimação existe mais é mínima.

\begin{tabular}{|c|c|c|c|c|c|c|c|}
\hline & 1986 & & 1987 & & & & \\
\hline & Nov & Dez & Jan & Fev & Mar & Abr & Ma i \\
\hline Inflaçăo & .2 & .2 & .4 & .5 & .4 & .4 & .5 \\
\hline Inflaçào Adicional & .0 & .1 & & -.1 & & .1 & \\
\hline Inflaçào Real & .2 & .3 & .4 & .4 & .4 & .5 & .5 \\
\hline Juro Real & 2.0 & 2.0 & 2.0 & 2.0 & 2.0 & 2.0 & 2.0 \\
\hline Juros Nominais & 2.2 & 2.3 & 2.4 & 2.4 & 2.4 & 2.5 & 2.6 \\
\hline Matéria Prima Cz\$ & 100.0 & 100.3 & 100.7 & 101.1 & 101.5 & 101.9 & 102.5 \\
\hline Prazo Créd. (dias) & 28 & 28 & 28 & 28 & 28 & 28 & 28 \\
\hline Desp. Financeiras & 2.1 & 2.2 & 2.3 & 2.3 & 2.2 & 2.3 & 2.4 \\
\hline Preço Final Cz\$ & 102.1 & 102.5 & 102.9 & 103.3 & 103.7 & $104 \cdot 3$ & 104.9 \\
\hline $\begin{array}{l}\text { Inflação Prevista } \\
\text { Inflaço Incremental }\end{array}$ & .2 & $\begin{array}{l}.4 \\
.2\end{array}$ & $\begin{array}{l}.5 \\
.1\end{array}$ & $\begin{array}{r}.4 \\
-.1\end{array}$ & .4 & .5 & .6 \\
\hline
\end{tabular}

Inflação superestimada em 6 meses $=0.1$

Esta superestimação acentuada depois de um congelamento. O efeito é diretamente proporcional ao salto inicial da inflação pós-congelamento. E por azar, o salto proporcional de 1\% para 3\% é muito maior do que o salto de $13 \%$ para $14 \%$, por exemplo. Por isto, este fenômeno é particularmente nefasto nos períodos de descongelamento.

Antes dos choques heterodoxos, este fenômeno existia, mas a inflação subia gradualmente embora de forma constante. A próxima simulação mostra porque a superestimação naquela época não era tão transparente.

Antes dos Planos Heterodoxos

A inflação subia pouco todo mês.

Depois congelamentos, a inflação sobe muito num único mês

\begin{tabular}{lrrrrrrr}
\hline & 1986 & \multicolumn{7}{c}{1987} & & & \\
& Nov & Dez & Jan & Fev & Mar & Abr & Mai \\
Inflaçăo & 13.5 & 13.5 & 13.9 & 14.4 & 15.2 & 16.1 & 17.1 \\
Inflaçăo Adicional & .0 & .2 & .2 & .2 & .2 & .2 & .2 \\
Inflaçào Real & 13.5 & 13.7 & 14.1 & 14.6 & 15.4 & 16.3 & 17.3 \\
Juro Real & 2.0 & 2.0 & 2.0 & 2.0 & 2.0 & 2.0 & 2.0 \\
Juros Nominais & 15.8 & 16.0 & 16.4 & 16.9 & 17.7 & 18.6 & 19.6 \\
Matéria Prima Cz\$ & 100.0 & 113.7 & 129.7 & 148.7 & 171.6 & 199.5 & 234.0 \\
Prazo Créd.(dias) & 28 & 28 & 28 & 28 & 28 & 28 & 28 \\
Desp. Financeiras & 14.6 & 16.9 & 19.7 & 23.4 & 28.2 & 34.4 & 42.6 \\
\hline Preço Final Cz\$ & 114.6 & 130.6 & 149.4 & 172.1 & 199.8 & 233.9 & 276.6 \\
Inflaçâo Prevista & 13.5 & 13.9 & 14.4 & 15.2 & 16.1 & 17.1 & 18.3 \\
Inflação Incremental & & .4 & .6 & .7 & .9 & 1.0 & 1.2
\end{tabular}

Inflação superestimada em 6 meses $=7.1$ 
Embora a simulação aponte para uma superestimação de somente 7,1\%, a menor até agora com exceção à simulação, americana, na realidade o efeito era muito menor, uma vez que o ciclo de indexação na época era semestral e não mensal como agora. Mesmo assim, em anos de maxi-desvalorizações, os efeitos da superestimação era bem nítidos.

A titulo de ilustração, a simulação seguinte mostra que em épocas de inflação declinante o índice é subestimado. Isto ocorreu e ocorre na inflação seguinte a um congelamento de preços. A pesar de dos aumentos de véspera, a inflação do mês seguinte normalmente é bastante reduzida, contrariando o bom senso. A causa é a redução dos valores dos preços a prazo, que subestima desta vez o índice geral de preços.

Quando a inflação cai, na inflação é SUB Estimada.

Embora os preços tendam a ser inflexíveis para baixo.

\begin{tabular}{lrrrrrrr} 
& Nov & Dez & Jañ & Fev & Mar & Abr & Mai \\
& 13.5 & 13.5 & 11.6 & 10.7 & 9.9 & 9.2 & 8.5 \\
Inflaçào & .0 & -1.0 & .0 & .0 & .0 & .0 & .0 \\
Inflaçáo Adicional & 13.5 & 12.5 & 11.6 & 10.7 & 9.9 & 9.2 & 8.5 \\
Inflaça Real & 2.0 & 2.0 & 2.0 & 2.0 & 2.0 & 2.0 & 2.0 \\
Juro Real & 15.8 & 14.8 & 13.8 & 12.9 & 12.1 & 11.4 & 10.7 \\
Juros Nominais & & & & & & & \\
Matéria Prima Cz\$ & 100.0 & 112.5 & 125.5 & 139.0 & 152.8 & 166.8 & 181.0 \\
Prazo Créd. (dias) & 28 & 28 & 28 & 28 & 28 & 28 & 28 \\
Desp. Financeiras & 14.6 & 15.4 & 16.1 & 16.7 & 17.2 & 17.6 & 18.0 \\
\hline Preço Final Cz\$ & 114.6 & 127.9 & 141.6 & 155.7 & 170.0 & 184.4 & 199.0 \\
Inflação Prevista & 13.5 & 11.6 & 10.7 & 9.9 & 9.2 & 8.5 & 7.9 \\
Inflaçăo Incremental & & -1.9 & -.9 & -.8 & -.7 & -.7 & -.6 \\
& & & & & & & \\
\hline
\end{tabular}

Inflação supcrestimada em 6 meses $=-4.8$

Vejamos o efeito de uma redução do prazo de crédito. O índice de preços perde parte de sue efeito acelerador, uma vez que os índices se tornam mais próximos da realidade por serem menos superestimados. Este fenômeno ocorre sempre que a inflação começa a perder controle, quando as empresas por cautela reduzem drasticamente os prazos de crédito.

Esta redução fornece um suspiro de uns dois meses na aceleração inflacionária, algo várias vezes observado na economia brasileira.

Redução no prazo de crédito reduz a inflação nominal.

Quando a inflação ameaça explodir as empresas reduzem prazo.

\begin{tabular}{|c|c|c|c|c|c|c|c|}
\hline & 1986 & & 1987 & & & & \\
\hline & Nov & Dez & Jan & Fev & Mar & Abr & Mai \\
\hline Inflação & 13.5 & 13.5 & 12.4 & 11.5 & 10.6 & 9.9 & 9.3 \\
\hline Inflaçâo Adicional & .0 & .0 & .0 & .0 & .0 & .0 & .0 \\
\hline Inflaçảo Real & 13.5 & 13.5 & 12.4 & 11.5 & 10.6 & 9.9 & 9.3 \\
\hline Juro Real & 2.0 & 2.0 & 2.0 & 2.0 & 2.0 & 2.0 & 2.0 \\
\hline Juros Nominais & 15.8 & 15.8 & 14.6 & 13.7 & 12.8 & 12.1 & 11.5 \\
\hline Matéria Prima Cz\$ & 100.0 & 113.5 & 127.6 & 142.2 & 157.3 & 172.9 & 189.1 \\
\hline Prazo Créd.(dias) & 28 & 26 & 26 & 26 & 26 & 26 & 26 \\
\hline Desp. Financeiras & 14.6 & 15.4 & 16.0 & 16.7 & 17.4 & 18.0 & 18.7 \\
\hline Preço Final $\mathrm{Cz} \$$ & 124.6 & 128.9 & 143.6 & 158.9 & 174.7 & 191.0 & 207.8 \\
\hline Inflaçăo Prevista & 13.5 & 12.4 & 11.5 & 10.6 & 9.9 & 9.3 & 8.8 \\
\hline Inflaçảo Incremental & & -1.1 & -.9 & -.8 & -.7 & -.6 & -.5 \\
\hline
\end{tabular}

Inflação superestimada em 6 meses $=-4.4$ 
Existem diversas soluções para resolver este problema, que como tudo na vida, são relativamente fáceis depois de se detectar os cernes da questão. Mas sua aceitação e, portanto, implantação, é que apresenta os grandes problemas.

Primeiro porque implica em mudar o calculo do índice. Para quem não esta absolutamente convicta do fenômeno, significará manipulação do índice e não adequação do índice à realidade.

Calculando-se o índice usando o valor presente dos preços, por exemplo, obraríamos os seguintes resultados:

Calculando corretamente - Preços pelo seu valor presente

Contabilidade a Valor Presente.

Impostos sobre o preço a vista.

\begin{tabular}{|c|c|c|c|c|c|c|c|}
\hline & 1986 & & 1987 & & & & \\
\hline & Nov & Dez & Jan & Fev & Mar & Abr & Mai \\
\hline Inflação & 1.0 & 1.0 & 4.5 & 4.5 & 4.5 & 4.5 & 4.5 \\
\hline Inflação Adicional & .0 & 3.5 & & & & & \\
\hline Inflaçào Real & 1.0 & 4.5 & 4.5 & 4.5 & 4.5 & 4.5 & 4.5 \\
\hline Juro Real & 2.0 & 2.0 & 2.0 & 2.0 & 2.0 & 2.0 & 2.0 \\
\hline Juros Nominais & 3.0 & 6.6 & 6.6 & 6.6 & 6.6 & 6.6 & 6.6 \\
\hline Matéria Prima CzS & 100.0 & 104.5 & 109.2 & 114.1 & 119.3 & 124.6 & 130.2 \\
\hline Prazo Créd. (dias) & 0 & .0 & 0 & 0 & 0 & 0 & 0 \\
\hline Desp. Financeiras & .0 & .0 & .0 & .0 & .0 & .0 & .0 \\
\hline Preço Final cz\$ & 100.0 & 104.5 & 109.2 & 114.1 & 119.3 & 124.6 & 130.2 \\
\hline Inflação Prevista & 1.0 & 4.5 & 4.5 & 4.5 & 4.5 & 4.5 & 4.5 \\
\hline Inflação Incremental & & 3.5 & .0 & .0 & .0 & .0 & .0 \\
\hline
\end{tabular}

Inflação superestimada em 6 meses $=.0$

A inflação seria corretamente calculada, e nas condições atuais se tornaria uma inflação inercial de $4,5 \%$, embora não necessariamente. Uma vez debelado este problema de superestimação, os planos para sanear as causas primárias da inflação poderão ter sucesso. Simulação acima prazo de crédito igual a prazo zero é equivalente a venda á vista.

Vejamos um resumo das 7 simulações, quanto a superestimação e a inflação do mês de maio (como ponto de comparação)

$\begin{array}{lcc}\text { Situação } & \text { Maio } & \text { Superestimação } \\ \text { Cálculo correto } & 4,5 & 0 \\ \text { Cruzado } & 22,8 & 20,1 \\ \text { Aumentando os Juros } & 28,1 & 26,7 \\ \text { Aumento de Prazo } & 39,1 & 48,4 \\ \text { Antes dos Planos } & - & 7,1 \\ \text { Nos Estado Unidos } & - & 0,1\end{array}$

O efeito exposto é bem mais complexas obviamente as implicações bem mais sutis, os meandros desta superestimação bem mais sinuosos, as implicações bem mais sutis, os meandros desta superestimação bem mais sinuosos, as conseqüências bem mais obscuras.

Os prazos de crédito não são uniformes, os salários nem sempre aumentam mensalmente, os impostos geram distorções especiais e uma simulação perfeita requer muito mais variável do que mostramos neste trabalho.

Mesmo assim as simulações mostram que uma inflação adicional de somente 3,5\% é capaz de gerar uma superestimação de inflação na ordem de $48 \%$ no prazo de seis meses. Mais do que o Déficit público e outras causas comummente apontadas como sendo o foco do processo brasileiro.

Uma vez identificado o problema, a solução se torna mais fácil de ser apresentada. Varias são as possibilidades:

A- Calcular os preços pelos valores a vista, o trazendo a valor presente os preços do atacado. os reajustes de salários não mais seriam efetuados pelos preços no varejo. A justificativa política é de que o consumidor deve colaborar no esforço de combate à inflação, procurando o preço mais barato. Isto já ocorre na prática, no exemplo que iniciamos com a dona da casa e o eletrodoméstico a grande disparidade de preço existente no varejo advém do fato de que os preços maiores são normalmente os comprados há 26 dias. Como ambos estão ainda dentro do prazo de crédito do fornecedor, não há necessidade de reajustes por causa da inflação. Estas remarcações somente ocorrem para os estoques já pagos, e portanto pertencente ao capital de giro da empresa e não do fornecedor. 
B- Conscientizar o varejo e adotar um sistema de "mark-up"sobre o valor presente das compras e não pelos valores constantes nas notas fiscais.

C- Mudar o sistema de cálculos do ICMS e IPI para que incida sobre o valor presente dos preços, pelas mesmas razões expostas acima.

Os índices de preço foram elaboradas em épocas diversas das atuais e não é uma questão de afirmar que os índices são mal calculados nem que a metodologia é causadora da inflação. Muitos índices adotam os preços no varejo, que teoricamente não deveriam embutir valores a prazo. O varejo não possui sistemas de contabilidade de custos a valor do presente, nem comummente adota "mark-ups" sobre o valor da nota de compra. É desta forma que os preços a varejo acabam captando o valor a prazo de crédito. O importante é calcular os índices que captem a inflação real, e não achar culpados pelas distorções que a própria inflação causa no sistema econômico brasileiro. 